JURNAL TERKNOSAINS

\title{
ANALISIS PENGARUH BENTUK TELAPAK KAKI TERHADAP KELELAHAN FISIK
}

\author{
Herianto dan Bonita Aminoto \\ Jurusan Teknik Mesin dan Industri Fakultas Teknik Universitas Gadjah Mada \\ Email:herianto@ugm.ac.id
}

\begin{abstract}
Physical activity over time can cause fatigue during exercise such as walking or light running. Physical fatigue effects on heart rate and blood pressure. Factors that can cause fatigue are gender, cardiovascular disease status, sport exercise habits, BMI (Body Mass Index) and study activities during a week. Physical fatigue also could be caused by factors shape of your foot, especially the form of flat feet/pesplanus in type 1, 2or 3. Subjects of this research were students of Industrial Engineering Gadjah Mada University ages 19 to 23 years with the aim of sampling techniques to the criteria of having normal or flat feet. The subjects run normally using a tread mill with a speed of 4 miles per hour for 6 minutes. The variables measured were heart rate and blood pressure. Heart rate was measured in three sessions among others before, during and after the experiment using a heart rate monitor while blood pressure was measured before and after the experiment. There are significant differences in systolic blood pressure before and after the experimental on indicator of sex, heart rate after experimental on indicator of disease status and heart rate on indicator exercise habit for normal feet. Then in the form of pesplanus foot type 1, there are significant differences like systolic and diastolic blood pressure after experimental on indicator of BMI (Body Mass Index) and systolic blood pressure on indicator of pre-experimental study activities during a week, in which a significant difference in respondents who did not have study activities of the respondents who went tocollegein6-10 hours. In the form of pesplanus foot type 2 there is a significant difference in heart rate when experimental on indicator of cardiovascular disease status.
\end{abstract}

Keywords: fatigue, foot surface shape, heart rate, blood pressure, treadmill

\begin{abstract}
ABSTRAK
Aktivitas fisik selama beberapa waktu dapat menyebabkan kelelahan saat berolahraga ringan seperti berjalan atau berlari. Kelelahan fisik mempengaruhi denyut jantung dan tekanan darah.Faktor yang dapat menyebabkan kelelahan yaitu jenis kelamin, status penyakit kardiovaskular, kebiasaan berolahraga, BMI dan jam kegiatan kuliah selama seminggu.Kelelahan fisik juga dapat disebabkan oleh faktor bentuk telapak kaki, terutama bentuk telapak kaki datar/pes planus tipe 1,2 dan 3. Penelitian ini dilakukan pada mahasiswa Program Studi Teknik Industri Universitas Gadjah Mada usia 19 sampai 23 tahun dengan teknik sampling bertujuan dengan kriteria memiliki telapak kaki normal atau datar. Untuk mengetahui tujuan penelitian tersebut dilakukan percobaan/eksperimen berjalan normal menggunakan treadmill dengan kecepatan 4 kilometer per jam selama 6 menit.Variabel yang diukur adalah denyut jantung dan tekanan darah.Denyut jantung diukur dalam tiga sesi yaitu sebelum, saat dan setelah eksperimen menggunakan heart rate monitor sedangkan tekanan darah diukur sebelum dan setelah eksperimen menggunakan tensimeter digital.Hasil yang didapatkan pada bentuk telapak kaki normal terdapat perbedaan signifikan pada tekanan darah sistolik pra dan pasca eksperimen indikator jenis kelamin, denyut jantung pasca eksperimen indikator status penyakit dan denyut jantung saat eksperimen indikator rutin berolahraga atau tidak. Lalu pada bentuk telapak kaki pes planus 1 terdapat perbedaan cukup signifikan seperti: tekanan darah sistolik dan diastolik pasca eksperimen indikator BMI (Body Mass Index) serta tekanan
\end{abstract}


darah sistolik pra eksperimen indikator kegiatan kuliah selama seminggu, di mana perbedaannya cukup signifikan pada responden yang tidak memiliki kegiatan kuliah dan responden yang kuliah 6-10 jam. Pada bentuk telapak kaki pes planus 2 terdapat perbedaan cukup signifikan pada denyut jantung saat eksperimen indikator status penyakit kardiovaskular.

Kata kunci: Kelelahan, Bentuk Telapak Kaki, Denyut Jantung, Tekanan Darah, Treadmill

\section{PENGANTAR}

Ergonomi adalah ilmu yang mempelajari interaksi manusia, mesin, dan lingkungan yang bertujuan untuk menyesuaikan pekerjaan dengan manusia. Antropometri merupakan bagian dari ilmu ergonomi yang berhubungan dengan dimensi tubuh manusia yang meliputi bentuk, ukuran dan kekuatan dan penerapannya untuk kebutuhan perancangan fasilitas aktivitas manusia.

Aktivitas fisik memerlukan energi untuk kontraksi otot yang berasal dari makanan dan oksigen. Aktivitas fisik selama beberapa waktu dapat menyebabkan kelelahan saat berolahraga ringan seperti berjalan atau berlari. Kaki merupakan bagian anggota gerak yang sangat penting untuk berjalan dan berfungsi sebagai tuas/pengungkit sehingga merupakan bagian penerima berbagai gaya deformitas sehingga bentuk tapak kaki yang leper tanpa lengkung kurang mampu berfungsi sebagai tuas atau pengungkit untuk mengungkit tubuh pada saat kaki akan meninggalkan pijakan pada proses berjalan. Lengkung kaki yang tidak tumbuh normal menyebabkan gangguan keseimbangan, tidak stabil, keluhan lelah bila berjalan lama, sepatu bagian tumit cepat aus, cedera berlebih dan rasa nyeri.

Aktivitas fisik juga berpengaruh pada denyut jantung sebelum dan sesudah beraktivitas seperti pada penelitian yang dilakukan oleh Irenne dengan metode naik turun tangga.Disimpulkan terdapat perubahan yang bermakna antara denyut nadi awal dan denyut nadi setelah naik turun tangga. Selain denyut nadi, tekanan darah juga dipengaruhi faktor seperti aktivitas fisik, emosi, stres, umur, jenis kelamin, status gizi/obesitas, minum alkohol dan merokok.

Salah satu penelitian tentang kelelahan fisik pada bentuk telapak kaki yang berbeda adalah Hubungan antara Derajat Lengkung Kaki dengan Tingkat Kemampuan Endurans pada Calon Jemaah Haji, 2007 oleh Lutfie.

Tujuan dari penelitian ini adalah untuk mengetahui adanya efek/pengaruh dari perbedaan bentuk telapak kaki pada mahasiswa Teknik Industri Universitas Gadjah Mada seperti pada penelitian sebelumnya[6].

Lutfie memakai metode uji berjalan selama 6 menit dengan menghitung $\mathrm{VO}_{2}$ maksimum pada calon jamaah haji Jakarta Timur tahun 2007 sebanyak 172 orang dengan cara mengambil sidik telapak kaki menggunakan tinta lalu mengecap telapak kaki pada kertas putih. Hasilnya menunjukkan calon jamaah haji dengan bentuk kaki datar/pes planus tingkat kemampuan endurans/kebugarannya kurang sehingga dinyatakan tidak mampu haji.Berikut macam-macam telapak kaki yang dikemukakan oleh Idris [3] pada Gambar 1.

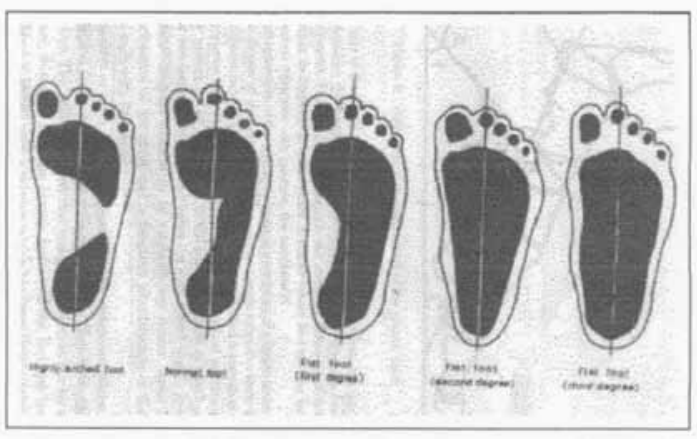

Gambar 1. Sidik Telapak Kaki Datar, Normal, Pes Planus Derajat 1, 2 dan 3

Pada penelitian yang dilakukan oleh Lutfie dipakai responden sebanyak 1920 pada calon jamaah haji sedangkan dalam penelitianini akan memakai responden yang berasal dari kalangan mahasiswa Teknik Industri Universitas Gadjah Mada sehingga akan diketahui apakah ada efek dari perbedaan bentuk telapak kaki dengan kelelahan fisik. 
Subjek dalam penelitian ini sebanyak 48 orang dengan pembagian 23 laki-laki dan 25 perempuan dengan rata-rata umur $21,48 \pm 1,24$ tahun. Penelitian dilakukan dalam beberapa tahap yang ditunjukan pada Gambar 2.

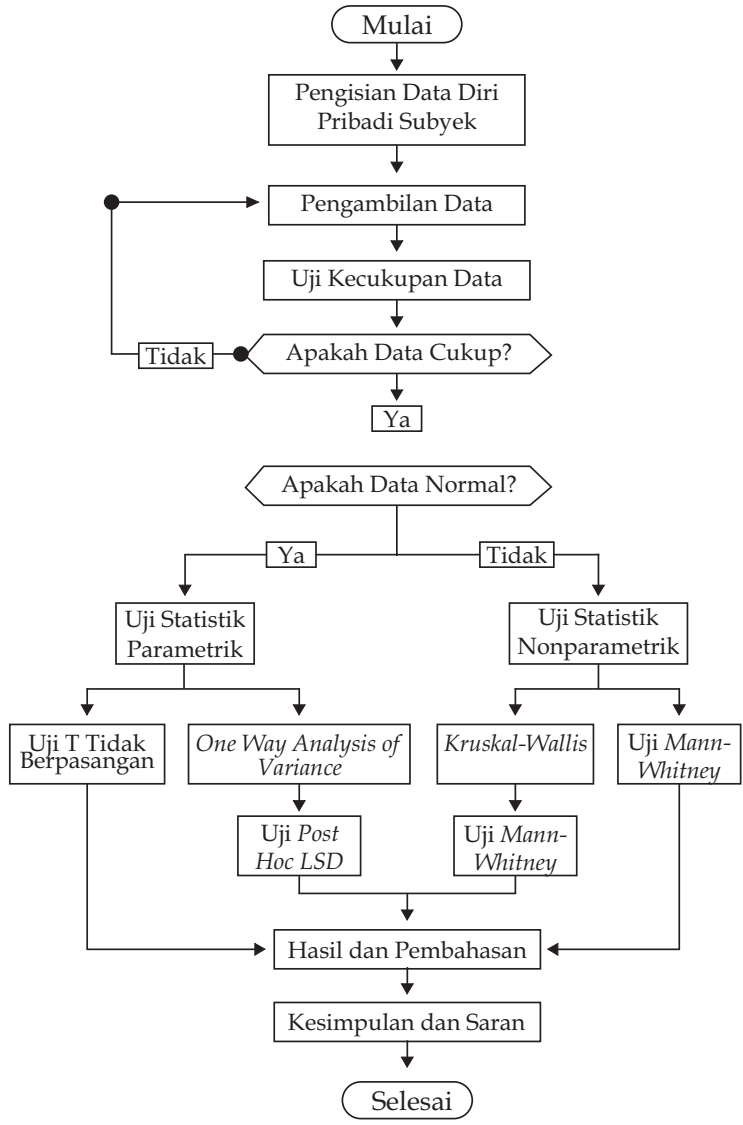

Gambar 2. Diagram Alir Penelitian

Metode pengambilan sampel dilakukan dengan teknik sampling non-random yaitu teknik purposive sampling (teknik sampling bertujuan) dari populasi mahasiswa Universitas Gadjah Mada Jurusan Teknik Industri dengan kriteria usia 19 sampai 23 tahun serta memiliki bentuk telapak kaki normal dan datar/pes planus tipe 1, 2 atau 3. Eksperimen dalam penelitian ini dilakukan dengan cara berjalan cepat di atas treadmill selama 6 menit dengan kecepatan 4 kilometer per jam.

Pengambilan data dilakukan pada variabel denyut jantung dan tekanan darah. Untuk variabel denyut jantung menggunakan alat pengukur denyut jantung (heart rate monitor) yang terdiri dari belt/sabuk dan jam tangan pengukur yang dipakaikan ke responden pada kondisi sebelum, saat dan setelah eksperimen. Untuk variabel tekanan darah digunakan sphygmomanometer/ tensimeter jenis digital pada kondisi sebelum dan setelah melakukan eksperimen. Sebelum eksperimen denyut jantung dan tekanan darah responden diukur dan dicatat. Pada saat eksperimen setiap satu menit denyut jantung responden dicatat dan terdapat denyut jantung maksimum saat melakukan eksperimen, di mana denyut jantung maksimum merupakan batas aman denyut jantung responden saat melakukan eksperimen dengan rumus 200 0,65* usia (dalam tahun) [1]. Kemudian setelah eksperimen denyut jantung dan tekanan darah responden diukur lagi dengan heart rate monitor dan tensimeter lalu dicatat dan dibandingkan hasilnya dengan sebelum dan saat eksperimen.

Data yang sudah diperoleh selanjutnya dilakukan uji statistik. Pengujian selanjutnya adalah uji signifikansi pada variabel denyut jantung dan tekanan darah pada masingmasing bentuk telapak kaki berdasarkan indikator-indikator seperti jenis kelamin, BMI (Body Mass Index), jam kegiatan kuliah selama seminggu, status penyakit kardiovaskular dan kebiasaan berolahraga dalam sebulan.

Pengujian Post Hoc atau uji perbedaan yang dapat mengetahui letak perbedaan pada indikator yang memiliki lebih dari dua kelompok perlu dilakukan jika nilai signifikansinya kurang dari 0,05.

\section{PEMBAHASAN \\ Selisih Variabel Denyut Jantung dan Tekanan Darah}

Setelah pengambilan data pada kondisi sebelum, saat dan setelah eksperimen dapat diketahui selisih denyut jantung dan tekanan darah pada masing-masing bentuk telapak kaki.Selisih denyut jantung dan tekanan darah sistolik dan diastolik untuk masing-masing bentuk telapak kaki (normal, pes planus 1 dan pes planus 2) dapat dilihat pada grafik yang ditampilkan di Gambar 3 dan Gambar 4. 


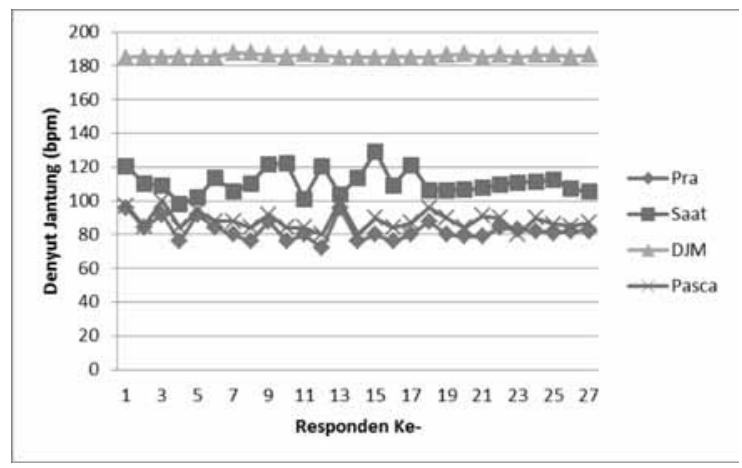

(a)

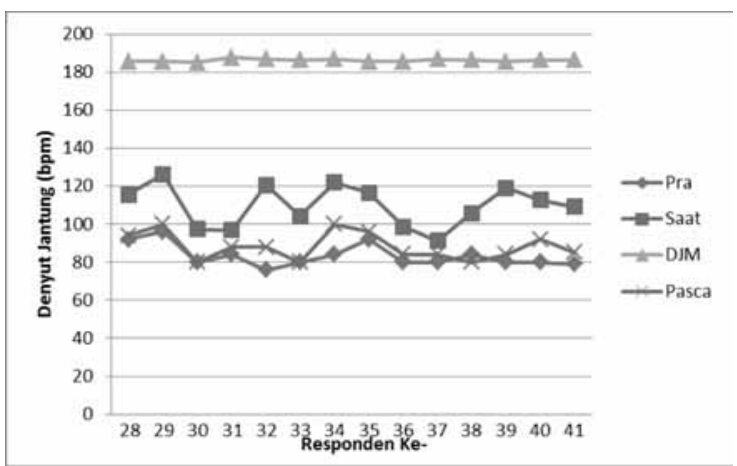

(b)

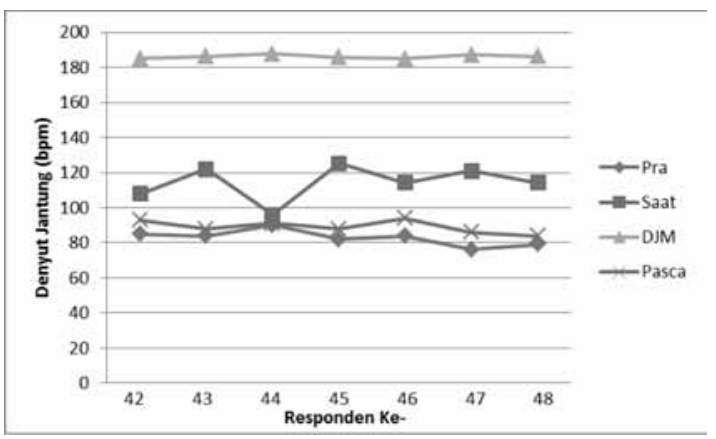

(c)

Gambar 3. Selisih Denyut Jantung Pada Bentuk Telapak Kaki Normal (a), Pes Planus 1 (b) dan Pes Planus 2 (c)

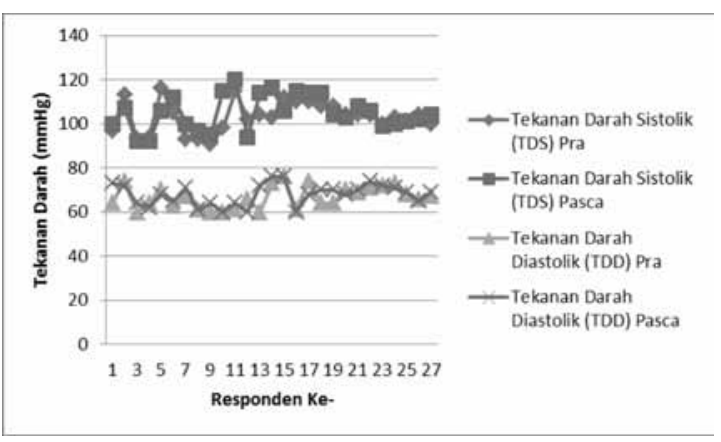

(a)

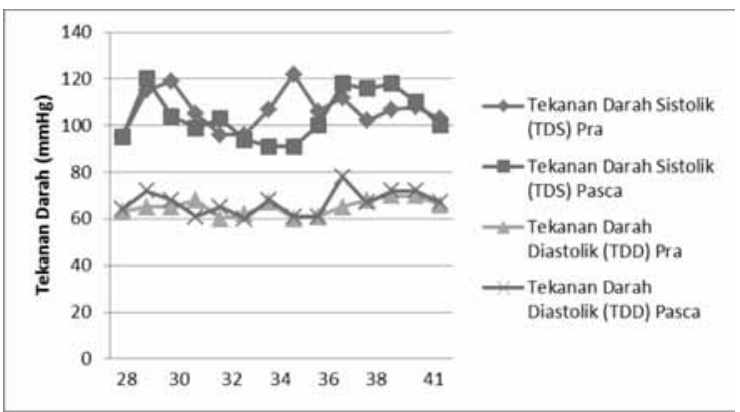

(b)

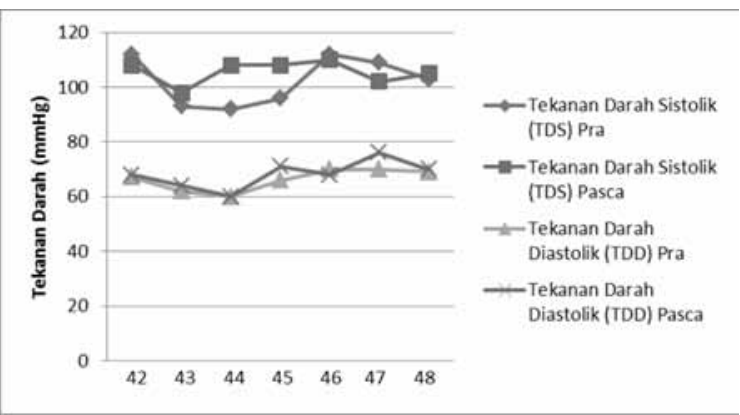

(c)

Gambar 4. Selisih Tekanan Darah Sistolik dan Diastolik Pada Bentuk Telapak Kaki Normal (a), Pes Planus 1 (b) dan Pes Planus 2 (c)

PadaGambar3adabeberapa selisih denyut jantung yang bernilai positif dan negatif pada kondisi pra dan pasca-eksperimen, di mana pada saat positif berarti denyut jantung pasca/ setelah eksperimen lebih rendah daripada denyut jantung pra/sebelum eksperimen sedangkan pada saat negatif denyut jantung pasca/setelah eksperimen lebih rendah daripada pra/sebelum eksperimen. Selisih denyut jantung yang memiliki perbedaan cukup jauh dapat dikarenakan responden kurang melakukan pemanasan saat akan melakukan eksperimen dan kurang terlatih dalam aktivitas berolahraga sehingga terjadi kenaikan denyut jantung yang cepat saat melakukan eksperimen.

Pada Gambar 4 ditunjukkan ada selisih tekanan darah sistolik dan diastolik yang bernilai positif dan negatif pada masingmasing tekanan darah, di mana pada saat positif berarti tekanan darah sistolik/ 
diastolik pasca eksperimen lebih tinggi daripada tekanan darah sistolik/diastolik pra eksperimen sedangkan pada saat negatif tekanan darah sistolik dan diastolik pasca eksperimen lebih rendah daripada pra eksperimen. Pada responden yang hasil selisih tekanan darah sistolik/diastoliknya positif dapat disebabkan kurangnya aktivitas pemanasan saat akan melakukan eksperimen atau tidak rutin berolahraga dan memiliki penyakit kardiovaskular sehingga memiliki waktu respon denyut jantung yang memerlukan waktu lebih lama kembali ke kondisi normal, sedangkan yang bernilai negatif mereka memerlukan waktu yang lebih cepat untuk kembali ke tekanan darah normal yang dapat disebabkan rutin berolahraga atau tidak memiliki penyakit kardiovaskular yang menyebabkan terjadi hal tersebut.

Faktor lain yang dapat menyebabkan perbedaan selisih baik yang bernilai positif, negatif ataupun memiliki selisih perbedaan yang cukup jauh seperti kesalahan pembacaan tekanan darah menggunakan tensimeter digital dan faktor psikologis seperti rasa gugup atau canggung bagi responden saat mengikuti eksperimen.

\section{Uji Statistika}

Pada pengujian statistika telah diperoleh data yang cukup berdasarkan perhitungan kecukupan data sedangkan dengan perhitungan kenormalan data terdapat data yang normal dan tidak normal.Jika data berdistribusi normal menggunakan uji parametrik (uji $t$ tidak berpasangan atau uji One Way ANOVA) sedangkan jika data berdistribusi tidak normal menggunakan uji nonparametrik (uji MannWhitney atau Kruskal-Wallis).

\section{Uji Signifikansi}

Pada data variabel yang memiliki dua kelompok variabel digunakan uji $t$ tidak berpasangan untuk data parametrik sedangkan untuk data nonparametrik digunakan uji Mann-Whitney.Uji tersebut digunakan untuk mengetahui adanya perbedaan signifikan dari masing-masing indikator pada variabel tersebut.Untuk data variabel yang memiliki lebih dari dua kelompok variabel digunakan uji One Way ANOVA untuk data parametrik dan uji Kruskal-Wallis untuk data nonparametrik. Uji tersebut digunakan untuk mengetahui adanya perbedaan signifikan dari masingmasing indikator pada variabel tersebut.Hasil uji signifikansi ditunjukkan pada Tabel 1 .

Tabel 1. Uji Signifikansi

\begin{tabular}{|c|c|c|c|c|c|c|c|c|c|c|}
\hline \multirow{3}{*}{$\begin{array}{c}\text { Bentuk } \\
\text { Telapak Kaki }\end{array}$} & \multirow{3}{*}{ Waktu Eksperimen } & \multirow{3}{*}{ Variabel } & \multirow{3}{*}{$\begin{array}{c}\text { Kenormalan } \\
\text { Data }\end{array}$} & \multicolumn{7}{|c|}{ Uji Signiflkansi } \\
\hline & & & & \multicolumn{3}{|c|}{ Uj T Tidak Berpas angan/Uji Mann-Whitury } & \multicolumn{2}{|c|}{ Ome Way ANOVA/Kruskal-Wallis } & \multicolumn{2}{|c|}{ Ome Way ANOVA/Kraskal-Walls } \\
\hline & & & & Jenis Kelamin & $\begin{array}{l}\text { Ada Atau } \\
\text { Tidaknya } \\
\text { Penyakit }\end{array}$ & $\begin{array}{c}\text { Rutin } \\
\text { Berolahrnga } \\
\text { Atau Tidak }\end{array}$ & $\begin{array}{c}\text { Varians Data (jika } \\
\text { memakai Ome Way } \\
\text { ANOVA) }\end{array}$ & $\begin{array}{l}\text { Body Mass } \\
\text { Inde X (BMII) }\end{array}$ & $\begin{array}{l}\text { Varians Data ("ika } \\
\text { me makai One Way } \\
\text { ANOVA) }\end{array}$ & Ke giatan Kuliat \\
\hline \multirow{7}{*}{ Normal } & \multirow{3}{*}{ Pra/Sebelum } & Denyut Jantung & Tidak Normal & $p>0,05$ & $p>0,05$ & $p>0,05$ & & $p>0,05$ & & $p>0,05$ \\
\hline & & Tekanan Darah Sistolik & Normal & $p<0,05$ & $p>0,05$ & $p>0,05$ & homogen & $p>0,05$ & homogen & $p>0,05$ \\
\hline & & Tekanan Darah Diastolik & Normal & $p>0,05$ & $p>0,05$ & $p>0,05$ & homogen & $p>0,05$ & homogen & $p>0,05$ \\
\hline & Saat & Denvut Jantung & Normal & $p>0,05$ & $p>0,05$ & $p<0,05$ & homogen & $p>0,05$ & homogen & $p>0,05$ \\
\hline & \multirow{3}{*}{ Pasca/Setelah } & Denyut Jantung & Normal & $p>0,05$ & $p<0,05$ & $p>0,05$ & homogen & $p>0,05$ & homogen & $p>0,05$ \\
\hline & & Tekanan Darah Sistolik & Normal & $p<0,05$ & $p>0,05$ & $p>0,05$ & homogen & $p>0,05$ & homogen & $p>0,05$ \\
\hline & & Tekanan Darah Diastolik & Normal & $\rho>0,05$ & $p<0,05$ & $p>0,05$ & homogen & $p>0,05$ & homogen & $p>0,05$ \\
\hline \multirow{7}{*}{ Pes Planus 1} & \multirow{3}{*}{ Pra/Sebelum } & Denyut Jantung & Tidak Normal & $p>0,05$ & $p>0,05$ & $p>0,05$ & & $p>0,05$ & & $p>0,05$ \\
\hline & & Tekanan Darah Sistolik & Normal & $p>0,05$ & $p>0,05$ & $p>0,05$ & & $p>0,05$ & homogen & $p<0,05$ \\
\hline & & Tekanan Darah Diastolik & Normal & $p>0,05$ & $p>0,05$ & $p>0,05$ & homogen & $p>0,05$ & homogen & $p>0,05$ \\
\hline & Saat & Denvut Jantung & Normal & $p>0,05$ & $p>0,05$ & $p>0,05$ & homogen & $p>0,05$ & & $p>0,05$ \\
\hline & \multirow{3}{*}{ Pasca/Setelah } & Denyut Jantung & Normal & $p>0,05$ & $p>0,05$ & $p>0,05$ & homogen & $p>0,05$ & homogen & $p>0,05$ \\
\hline & & Tekanan Darah Sistolik & Normal & $p>0,05$ & $p>0,05$ & $p>0,05$ & homogen & $p<0,05$ & homogen & $p>0,05$ \\
\hline & & Tekanan Darah Diastolik & Normal & $p>0,05$ & $p>0,05$ & $p>0,05$ & homogen & $p<0,05$ & homogen & $p>0,05$ \\
\hline \multirow{7}{*}{ Pes Planus 2} & \multirow{3}{*}{ Pra/Sebelum } & Denvut Jantung & Normal & $p>0,05$ & $p>0,05$ & $p>0,05$ & hamogen & $p>0,05$ & homogen & $p>0,05$ \\
\hline & & Tekanan Darah Sistolik & Normal & $p>0,05$ & $p>0,05$ & $p>0,05$ & homogen & $p>0,05$ & homogen & $p>0,05$ \\
\hline & & Tekanan Darah Diastolik & Normal & $p>0,05$ & $p>0,05$ & $p>0,05$ & homogen & $p>0,05$ & homogen & $p>0,05$ \\
\hline & Saat & Denyut Jantung & Normal & $p>0,05$ & $p<0,05$ & $p>0,05$ & homogen & $p>0,05$ & homogen & $p>0,05$ \\
\hline & \multirow{3}{*}{ Pasca/Setelah } & Denvut Jantung & Normal & $p>0,05$ & $p>0,05$ & $p>0,05$ & homogen & $p>0,05$ & Tidsk homogen & $p>0,05$ \\
\hline & & Tekanan Darah Sistolik & Normal & $p>0,05$ & $p>0,05$ & $p>0,05$ & homogen & $p>0,05$ & homogen & $p>0,05$ \\
\hline & & Tekanan Darah Diastolik & Normal & $p>0,05$ & $p>0,05$ & $p>0,05$ & homogen & $p>0,05$ & homogen & $p>0,05$ \\
\hline
\end{tabular}




\section{Uji Beda pada Indikator Lebih Dari Dua Kelompok}

Pada data variabel yang diujikan pada indikator yang memiliki lebih dari dua kelompok seperti BMI (underweight, normal, dan overweight) dan jam kegiatan kuliah (0 jam, 1-5 jam, 6-10 jam dan lebih dari 10 jam) jika nilai signifikansinya kurang dari 0,05, maka perlu dilakukan uji beda. Uji beda yang dilakukan untuk data variabel denyut jantung atau tekanan darah parametrik One Way ANOVA akan digunakan uji Post Hoc LSD sedangkan untuk data variabel nonparametrik akan digunakan uji MannWhitney.

Setelah dilakukan pengujian signifikansi ternyata pada data variabel yang memiliki lebih dari dua kelompok indikator hanya ditemukan perbedaan pada kegiatan kuliah mahasiswa selama seminggu pada bentuk telapak kaki pes planus 1 . Berikut hasil uji beda ditunjukkan pada Tabel2.

Tabel 2. Multiple Comparisons

\begin{tabular}{|c|c|c|c|c|c|c|}
\hline \multirow{2}{*}{$\begin{array}{l}\text { (I) Jam Kuliah } \\
\text { Selama Seninggu }\end{array}$} & \multirow{2}{*}{$\begin{array}{l}\text { (J) Jam Kuliah } \\
\text { Selama Seminggu }\end{array}$} & \multirow{2}{*}{$\begin{array}{c}\text { Mean } \\
\text { Difference (1- } \\
\text { J) }\end{array}$} & \multirow[b]{2}{*}{ Std Erros } & \multirow[b]{2}{*}{ Sig. } & \multicolumn{2}{|c|}{$95 \%$ Confidence Interval } \\
\hline & & & & & Lower Bound & Upper Bound \\
\hline \multirow[t]{2}{*}{$0 \mathrm{Jam}$} & 6-10 Jam & $11.60000^{\circ}$ & 3.85867 & .012 & 3.1071 & 20.0929 \\
\hline & Lebih Dari $10 \mathrm{Jam}$ & 1.50000 & 5.28370 & .782 & -10.1294 & 13.129 \\
\hline \multirow[t]{2}{*}{ 6-10 Jam } & $0 \mathrm{Jam}$ & $-11.60000^{\circ}$ & 3.85867 & .012 & -20.0920 & -3.1071 \\
\hline & Leblh Dari $10 \mathrm{Jam}$ & -10.10000 & 5.51354 & .094 & -222352 & 2.0352 \\
\hline \multirow[t]{2}{*}{ Lebih Dari $10 \mathrm{Jam}$} & $0 \mathrm{Jam}$ & -1.50000 & 5.28370 & .782 & -13.1294 & 10.1294 \\
\hline & 6-10 Jam & 10.10000 & 5.51354 & .094 & -2.0352 & 22.2352 \\
\hline
\end{tabular}

Pada tabel diatas terlihat bahwa terdapat perbedaan signifikan antara mahasiswa yang tidak memiliki kegiatan kuliah (0 jam) dengan mahasiswa yang memiliki kegiatan kuliah selama 6-10 jam secara statistik. Untuk responden yang tidak memiliki kegiatan kuliah (0 jam) dengan responden yang memiliki kegiatan kuliah selama lebih dari 10 jam dan responden yang memiliki kegiatan kuliah selama 6-10 jam dengan responden berkegiatan kuliah lebih dari 10 jam tidak mengalami perbedaan yang signifikan.

\section{SIMPULAN}

Berdasarkan analisis pengaruh bentuk telapak kaki terhadap kelelahan fisik, dapat ditarik kesimpulan sebagai berikut:

Pada bentuk telapak kaki normal ditemukan beberapa perbedaan cukup signifikan, yaitu: variabel tekanan darah sistolik pra dan pasca eksperimen indikator jenis kelamin, denyut jantung pasca eksperimen indikator status penyakit, dan denyut jantung saat eksperimen indikator rutin berolahraga atau tidak. Lalu pada bentuk telapak kaki pes planus 1 terdapat perbedaan cukup signifikan seperti: tekanan darah sistolik dan diastolik pascaeksperimen indikator BMI (Body Mass Index) serta tekanan darah sistolik pra eksperimen indikator kegiatan kuliah selama seminggu, di mana perbedaannya cukup signifikan pada responden yang tidak memiliki kegiatan kuliah dan responden yang kuliah 6-10 jam. Pada bentuk telapak kaki pes planus 2 terdapat perbedaan cukup signifikan pada denyut jantung saat eksperimen indikator status penyakit.

Dari hasil yang telah didapat diketahui bahwa indikator-indikator yang mempengaruhi variabel denyut jantung dan tekanan darah sistolik maupun diastolik memiliki peran yang cukup berpengaruh pada bentuk telapak kaki normal, pes planus 1, dan pes planus 2. Jika melihat selisih jumlah denyut jantung dan tekanan darah sistolik maupun diastolik yang sebagian besar perbedaannya tidak terlalu jauh, maka selisih tersebut terjadi karena aktivitas eksperimen yang tergolong ringan dan waktu eksperimen cukup singkat. Faktor-faktor lain juga dapat berpengaruh seperti kesalahan pembacaan tekanan darah menggunakan tensimeter digital dan faktor psikologis seperti rasa gugup atau canggung bagi responden saat mengikuti eksperimen. 


\section{DAFTAR PUSTAKA}

Bridger, R.S., 1995, Introduction to Ergonomics, International Edition, Mc-Graw Hill, Inc., Singapore.

Fitrihana, N., 2008, Antropometri, [Diakses secara online 15 November 2011]. URL: http:/ / batikyogya.wordpress. com/2008/08/30/274/

Idris, H.F., 2010, Filogeni dan Ontogeni Lengkung Kaki Manusia, Majelis Kedokteran Indonesia vol.60 no.2, Fakultas Kedokteran Universitas Indonesia.

Irenne, E.,M.,S., 2006, Perubahan Denyut Nadi pada Mahasiswa Setelah Aktivitas
Naik Turun Tangga, Artikel Karya Tulis Ilmiah, Fakultas Kedokteran, Universitas Diponegoro, Semarang.

Kurniawan, 2010, Perbedaan Tekanan Darah Tenaga Kerja Sebelum dan Sesudah Terpapar Tekanan Panas di Industri Mebel CV. Gion \& Rahayu Kartasura, Sukoharjo Jawa Tengah, Skripsi Diploma IV Fakultas Kedokteran, Universitas Sebelas Maret, Surakarta.

Lutfie, 2010, Hubungan antara Derajat Lengkung Kaki dengan Tingkat Kemampuan Endurans pada Calon Jemaah Haji, 2007, Hasil Penelitian pp. 343-346, Universitas Islam Negeri, Jakarta. 